\title{
The effects of zooprophylaxis and other mosquito control measures against malaria in Nouna, Burkina Faso Shelby S Yamamoto*1, Valérie R Louis ${ }^{1}$, Ali Sié2 and Rainer Sauerborn ${ }^{1}$
}

\author{
Address: ${ }^{1}$ Institute of Public Health, University of Heidelberg, Im Neuenheimer Feld 324, 69120 Heidelberg, Germany and ${ }^{2}$ Centre de Recherche \\ en Santé de Nouna, BP 02, Nouna, Burkina Faso \\ Email: Shelby S Yamamoto* - shelby.yamamoto@urz.uni-heidelberg.de; Valérie R Louis - valerie.louis@urz.uni-heidelberg.de; \\ Ali Sié - alisie.crsn@fasonet.bf; Rainer Sauerborn - rainer.sauerborn@urz.uni-heidelberg.de \\ * Corresponding author
}

Published: 9 December 2009

Malaria Journal 2009, 8:283 doi:10.1 186/1475-2875-8-283
Received: II May 2009

Accepted: 9 December 2009

This article is available from: http://www.malariajournal.com/content/8/I/283

(C) 2009 Yamamoto et al; licensee BioMed Central Ltd.

This is an Open Access article distributed under the terms of the Creative Commons Attribution License (http://creativecommons.org/licenses/by/2.0), which permits unrestricted use, distribution, and reproduction in any medium, provided the original work is properly cited.

\begin{abstract}
Background: In the absence of large scale, organized vector control programmes, individual protective measures against mosquitoes are essential for reducing the transmission of diseases like malaria. Knowledge of the types and effectiveness of mosquito control methods used by households can aid in the development and promotion of preventive measures.
\end{abstract}

Methods: A matched, population-based case control study was carried out in the semi-urban region of Nouna, Burkina Faso. Surveys and mosquito captures were conducted for each participating household. Data were analysed using conditional logistic regression and Pearson's product-moment correlations.

Results: In Nouna, Burkina Faso, the main types of reported mosquito control measures used included sleeping under bed nets (insecticide-treated and untreated) and burning mosquito coils. Most of the study households kept animals within the compound or house at night. Insecticide house sprays, donkeys, rabbits and pigs were significantly associated with a reduced risk of malaria only in univariate analyses.

Conclusion: Given the conflicting results of the effects of zooprophylaxis from previous studies, other community-based preventive measures, such as bed nets, coils and insecticide housespraying, may be of more benefit.

\section{Background}

Africa is particularly vulnerable to malaria for several reasons, including being exposed to the most severe form of the disease, having inadequate resources to bear the economic burden of the consequences and having to cope with the lack of proper infrastructure to effectively treat cases [1]. Hence, prevention of the disease becomes paramount. The use of individual methods of protection are particularly important, especially in areas lacking any formal mosquito control programmes, like Burkina Faso.
Bed nets, window screens, house sprays, ceilings, closed eaves and in some cases, zooprophylaxis can reduce the risk of malaria [2-6]. The evaluation of the different types of mosquito control methods used by households may be used to aid in the development and promotion of preventive measures that can be more readily integrated into communities. Thus, the aim of this study was to assess the reported use of different mosquito control methods among residents and their effects on the risk of malaria in the semi-urban area of Nouna, Burkina Faso. 


\section{Methods \\ Study site}

The study site of Nouna, Burkina Faso is located in the Kossi province, approximately $300 \mathrm{~km}$ from the capital city of Ouagadougou. Average annual rainfall in the region is about $700 \mathrm{~mm}$. The area is holoendemic for Plasmodium falciparum malaria although the peak transmission season is from June to October, during the wet season. Malaria vectors in the region include Anopheles gambiae, Anopheles funestus and Anopheles arabiensis. However, the predominant malaria vector is An. gambiae.

\section{Study design and population}

A population-based, 1:2 matched case-control study was carried out with 117 cases and 221 controls. Cases included women (15-45 years) and children ( $\leq 9$ years) recruited from those who were tested for malaria at the Centre de Recherche en Santé de Nouna Laboratory. The malaria risks posed to children are high in this region with the incidence estimated as 0.21 per child per month [7]. In addition, women of child-bearing age were included as they are often the primary caretakers of families and thus their health can affect entire households. Uncomplicated malaria cases were confirmed by thin and thick blood smears. Cases were matched to controls who did not visit the laboratory for malaria testing during the period of recruitment. Controls were selected from an extensive Demographic Surveillance System (DSS) database, which includes recent demographic and health data from 74,000 residents in Nouna and the surrounding areas [8]. Matching criteria included age ( \pm 3 years), sex, ethnicity and residence (town sector).

\section{Data collection and analysis}

Respondents (women and caretakers of the recruited children) were interviewed about different household protective measures against mosquitoes during the wet season. Mosquito captures were also performed over the course of one night for each household. Battery-powered light traps (CDC) with incandescent bulbs were used to capture mosquitoes in the sleeping rooms of the cases and controls. The trap was suspended above the floor and mounted close to the bed of the case or control but outside any mosquito nets. Pyrethrum spray captures were also performed the following morning. White drop cloths were laid down on the floors and a locally available insecticide was applied to the walls, furniture and roof for approximately one minute after closing the doors and windows. The participants were instructed to follow their usual daily mosquito control routines.

The responses were analyzed with SAS 9.1 (SAS Institute Inc., Cary, NC, USA) using univariate and multivariate conditional logistic regression. Those variables significant in univariate analyses at the $P=0.20$ level were subse- quently modeled by multivariate analysis. Multivariate models were adjusted for reported bed net use (yes/no) and level of education (none, primary, secondary or higher).

\section{Results}

The demographic characteristics of the cases and controls were similar (e.g. religion, household size, relationship of the respondent to the household head). An exception was the highest reported level of education. More cases than controls reported having secondary education or higher $(\mathrm{OR}=2.35$, 95\%CI: 1.18-4.70), therefore this variable was included as a potential confounder in multivariate models.

Most cases (99.2\%) and controls (98.6\%) reported using at least one mosquito preventive measure during the wet season. These included mainly sleeping under bed nets (both insecticide-treated and untreated) and burning mosquito coils (Table 1). Few used smoke from burned plant material regularly ( $\geq$ once per week) as a means to repel mosquitoes. Of those households that did, plants were burned mostly in the bedroom (11.2\%) and the living areas $(6.5 \%)$.

Several different types of animals were also owned or kept by the households. Animals were frequently kept within household compounds by both the cases $(89.6 \%)$ and controls $(87.2 \%)$ at night. Of the different types of livestock, cattle were most often found within the compound (Table 2). Donkeys were found to be significantly and positively correlated with female An. gambiae abundance in sleeping rooms (Pearson's $r=0.21, P=0.0002$ ). Separate analyses by unfed (Pearson's $r=0.16, P=0.0045$ ), fed (Pearson's $r=0.22, P<0.0001$ ) and sub-gravid (Pearson's $r=0.16, P=0.02$ ) status also produced significant correlations. No associations were found with any other types of animals.

Reported use of insecticide-treated and untreated bed nets as well as mosquito coils did not significantly affect the risk of malaria in univariate analyses (Table 3). Con-

Table I: Frequency of different reported mosquito control methods used in Nouna during the rainy season

\begin{tabular}{lcc}
\hline Type of mosquito control & Cases (\%) & Controls* (\%) \\
\hline Untreated bed net** & $61(52.1)$ & $112(50.7)$ \\
Insecticide-treated bed net** & $64(54.7)$ & $109(49.3)$ \\
Mosquito coils & $79(67.5)$ & $142(64.3)$ \\
Insecticide house sprays & $16(13.6)$ & $14(6.3)$ \\
Smoke from plants ( $\geq$ once per week) & $13(11.1)$ & $32(14.5)$ \\
\hline
\end{tabular}

\footnotetext{
* Pooled controls (control I and control 2)

** Some case and control households reported using both insecticidetreated and untreated nets
} 
Table 2: Types of animals kept within compounds or houses at night

\begin{tabular}{lcc}
\hline Animals kept in compound & Cases (\%) & Controls* (\%) \\
\hline Poultry & $60(51.3)$ & $108(48.9)$ \\
Cows & $56(47.9)$ & $114(51.6)$ \\
Sheep & $49(41.9)$ & $101(45.7)$ \\
Donkeys & $29(24.8)$ & $77(34.8)$ \\
Goats & $26(22.2)$ & $47(21.3)$ \\
Cats & $26(22.2)$ & $43(19.5)$ \\
Dogs & $25(21.4)$ & $36(16.3)$ \\
Others (e.g. rabbits) & $11(9.4)$ & $36(16.3)$ \\
Pigs & $3(2.6)$ & $20(9.1)$ \\
Horses & $0(0.0)$ & $1(0.5)$ \\
\hline
\end{tabular}

* Pooled controls (control I and control 2)

versely, when animals such as donkeys, rabbits and pigs were kept within compounds, a statistically significant protective effect was observed. An effect was not found with other animals such as cows, sheep, goats and poultry. Nonetheless, no variables included in multivariate models remained significant $(P<0.05)$, after adjusting for reported bed net use and level of education.

\section{Discussion}

Most of the respondents reported using some protective measures against mosquitoes during the wet season, a finding also echoed by Samuelsen et al [9]. Sleeping under bed nets and burning mosquito coils were the most popular forms of control during the rainy season. In fact, reported bed net use was very high. This could have been the result of promotions in the region encouraging the use

Table 3: Univariate analysis of the effects of different mosquito control practices on malaria risk

\begin{tabular}{llll}
\hline Description & OR & $\mathbf{9 5 \%} \mathbf{C I}$ & P-value \\
\hline $\begin{array}{l}\text { Type of mosquito control } \\
\text { Untreated bed net }\end{array}$ & 1.04 & $0.66-1.63$ & 0.88 \\
Insecticide-treated bed net & 1.23 & $0.79-1.93$ & 0.36 \\
Mosquito coils & 1.24 & $0.73-2.00$ & 0.47 \\
Insecticide house sprays & $\mathbf{2 . 4 9}$ & $\mathbf{1 . 1 1 - 5 . 5 9}$ & $\mathbf{0 . 0 3}$ \\
Smoke from plants & 0.74 & $0.35-1.56$ & 0.43 \\
& & & \\
Animals kept in compound & & & \\
Poultry & 1.14 & $0.68-1.90$ & 0.63 \\
Cows & 0.84 & $0.45-1.54$ & 0.57 \\
Sheep & 0.84 & $0.51-1.37$ & 0.48 \\
Donkeys & $\mathbf{0 . 5 9}$ & $\mathbf{0 . 3 4 - 1 . 0 1}$ & $\mathbf{0 . 0 5}$ \\
Goats & 1.08 & $0.60-1.93$ & 0.80 \\
Cats & 1.17 & $0.66-2.08$ & 0.59 \\
Dogs & 1.41 & $0.73-2.73$ & 0.31 \\
Others (i.e. rabbits) & $\mathbf{0 . 5 2}$ & $\mathbf{0 . 2 5}-1.09$ & $\mathbf{0 . 0 9}$ \\
Pigs & $\mathbf{0 . 2 6}$ & $\mathbf{0 . 0 7 - 0 . 8 9}$ & $\mathbf{0 . 0 3}$ \\
\hline
\end{tabular}

OR, odds ratio

$95 \% \mathrm{Cl}, 95 \%$ confidence interval

Bolded values are those significant at the $P<0.20$ level of insecticide-treated bed nets [3]. However, actual bed net use was not investigated in this study and could have been over-reported by the respondents, particularly since knowledge of the protective effects of bed nets does not necessarily translate into actual net use [10]. Insecticide house sprays were not a popular method of mosquito control in Nouna, likely because of the costs associated with such measures (Ouédraogo pers com. 2008). Similarly, smoke from the burning of plant material was also not as extensively used as in other regions like The Gambia [11].

The evidence regarding the effectiveness of zooprophylaxis is generally not clear. Keeping animals near houses can shift the biting behaviour of mosquitoes away from people and, therefore, mitigate malaria risk [12]. Conversely, sharing the house with livestock could also increase the risk of malaria. Greater numbers of mosquitoes may be initially attracted to households because of the presence of animals but then end up preferentially feeding on humans $[13,14]$. In The Gambia, it was found that animals conferred little or no protection against $A n$. gambiae and that the presence of cattle did not result in greater numbers of zoophilic species or a change in species composition. Moreover, the human blood index (HBI), or proportion of human-fed mosquitoes, was not altered among indoor resting mosquitoes between households with and without cattle [15].

In this study, most domestic animals sleeping within the compound or house were not associated with either an increased or decreased risk of malaria. Donkeys, rabbits and pigs, however, were associated with some zooprophylactic effect in univariate analyses. One possible explanation for the protective effect observed in this study could be that if vector breeding sites are closer to animal enclosures than to houses, mosquitoes may choose to feed on livestock as opposed to humans $[16,17]$. We observed significant, positive correlations between donkeys and the abundance of female An. gambiae mosquitoes captured in the sleeping rooms of the participants. This could suggest that donkeys, in particular, attract mosquitoes. Likewise, Pålsson et al [18] found that pigs, but not goats, were associated with increased numbers of mosquitoes collected from bedrooms in Guinea Bissau. Nonetheless, when bed net use or other behaviours, such as staying indoors are considered, animals may be a more accessible blood meal source $[19,20]$. It is also possible that certain types of animals, in particular equines such as horses and donkeys, exert stronger zooprophylactic effects. Bøgh et al [21] observed that the preference of An. gambiae for horses was strong in The Gambia, although since horse ownership was also very high, accessibility may have also influenced host choice. Another study in The Gambia also found that horses located near houses were correlated with lower 
numbers of mosquitoes in rooms, whereas no significant association was found with cattle [22]. Additional evidence suggests that the An. gambiae mosquitoes found in certain areas of West Africa may be less anthropophilic compared to those found in other areas, which may also explain some of the zooprophylactic effects observed in the study $[23,24]$.

Zooprophylaxis may lower the risk of malaria in this region. However, before this method of mosquito control could be recommended, other factors need be considered such as the potential for increased mosquito survival from greater feeding success or the creation of additional vector breeding sites from hoof prints, animal enclosures and water tanks $[25,26]$. It would also be necessary to further investigate separately the impact, in particular, of donkey, rabbit and pig proximity on malaria outcome and acquire more knowledge about mosquito anthropophilic biting behaviour in the area.

A study limitation was that mosquito captures were only conducted for one night. As a result, there was no way to determine if the species composition and counts obtained were representative of the conditions typically found in households. Nonetheless, cases and controls were largely sampled on the same day to avoid confounding from weather conditions. Also, sampling was not carried out on public holidays or other days that might have affected collections. Therefore, cases and controls were assumed to be equally affected by environmental factors and any bias non-differential. An additional limitation of this study was that active testing for malaria among the controls did not occur before recruitment, which may have biased the results towards the null. However, no controls reported having malaria during the recruitment period and none from the second field season had a fever $\left(\geq 37.5^{\circ} \mathrm{C}\right)$ at the time of data collection.

\section{Conclusion}

Given the infrequent use of smoke from the burning of plants and likely respiratory side effects as well as the interesting but unconfirmed results of zooprophylaxis, other measures to protect against mosquitoes may be of greater benefit in this region. Bed nets and mosquito coils have already gained wide acceptance and should be further encouraged. Community-based house spraying programmes may also be an effective tool.

\section{Competing interests}

The authors declare that they have no competing interests.

\section{Authors' contributions}

SY, AS, RS were responsible for designing the study, data collection was conducted by SY and AS, SY and VRL examined, analysed and interpreted the data, SY, VRL and RS drafted the paper. All authors read, edited and approved the final manuscript.

\section{Acknowledgements}

The authors would like to express their gratitude to all of the members of the research team, the study participants and the Centre de Recherche en Santé de Nouna. We would also like to acknowledge the financial support of the Deutsche Forschungsgemeinschaft Graduiertenkolleg 793 (German Research Foundation) for this study.

\section{References}

I. World Health Organization: The Africa Malaria Report 2006. Regional Offices for Africa and Eastern Mediterranean 2006.

2. Lindsay SW, Jawara M, Paine K, Pinder M, Walraven GE, Emerson PM: Changes in house design reduce exposure to malaria mosquitoes. Trop Med Int Health 2003, 8:5I 2-5I7.

3. Müller O, Traore C, Kouyate B, Ye Y, Frey C, Coulibaly B, Becher H: Effects of insecticide-treated bednets during early infancy in an African area of intense malaria transmission: a randomized controlled trial. Bull World Health Organ 2006, 84: $120-126$.

4. Oesterholt MJ, Bousema IT, Mwerinde OK, Harris C, Lushino P, Masokoto A, Mwerinde H, Mosha FW, Drakeley CJ: Spatial and temporal variation in malaria transmission in a low endemicity area in northern Tanzania. Malar J 2006, 5:98.

5. Guthmann JP, Hall AJ, Jaffar S, Palacios A, Lines J, Llanos-Cuentas A: Environmental risk factors for clinical malaria: a case-control study in the Grau region of Peru. Trans R Soc Trop Med Hyg 200I, 95:577-583.

6. Mahande A, Mosha F, Mahande J, Kweka E: Feeding and resting behaviour of malaria vector, Anopheles arabiensis with reference to zooprophylaxis. Malar J 2007, 6:100.

7. Traoré C: Epidemiology of malaria in a holoendemic area of rural Burkina Faso. Ph.D Thesis Heidelberg, Germany: University of Heidelberg; 2003.

8. INDEPTH: An International Network of Field Sites with Continuous Demographic Evaluation of Populations and Their Health in Developing Countries. Indepth Network. 2003. 17 6-2008

9. Samuelsen H, Toe LP, Baldet T, Skovmand O: Prevention of mosquito nuisance among urban populations in Burkina Faso. Soc Sci Med 2004, 59:2361-237I.

10. Opiyo P, Mukabana WR, Kiche I, Mathenge E, Killeen GF, Fillinger U: An exploratory study of community factors relevant for participatory malaria control on Rusinga Island, western Kenya. Malar J 2007, 6:48.

II. Snow RW, Bradley AK, Hayes R, Byass P, Greenwood BM: Does woodsmoke protect against malaria? Ann Trop Med Parasitol | 987, 81:449-451.

12. World Health Organization: Manual on environmental management for mosquito control with special emphasis on malaria vectors. Geneva, World Health Organization; 1982

13. Ghebreyesus TA, Haile M, Witten KH, Getachew A, Yohannes M, Lindsay SW, Byass P: Household risk factors for malaria among children in the Ethiopian highlands. Trans $R$ Soc Trop Med Hyg 2000, 94:|7-2|.

14. Deressa W, Ali A, Berhane Y: Household and socioeconomic factors associated with childhood febrile illnesses and treatment seeking behaviour in an area of epidemic malaria in rural Ethiopia. Trans R Soc Trop Med Hyg 2007, I 0 I:939-947.

15. Bøgh C, Clarke SE, Pinder M, Sanyang F, Lindsay SW: Effect of passive zooprophylaxis on malaria transmission in The Gambia. I Med Entomol 200I, 38:822-828.

16. Sota T, Mogi M: Effectiveness of zooprophylaxis in malaria control: a theoretical inquiry, with a model for mosquito populations with two bloodmeal hosts. Med Vet Entomol 1989, 3:337-345.

17. Saul A: Zooprophylaxis or zoopotentiation: the outcome of introducing animals on vector transmission is highly dependent on the mosquito mortality while searching. Malar $J 2003$, 2:32.

18. Pålsson K, Jaenson TG, Dias F, Laugen AT, Bjorkman A: Endophilic Anopheles mosquitoes in Guinea Bissau, west Africa, in rela- 
tion to human housing conditions. J Med Entomol 2004, 4l:746-752.

19. Burkot TR: Non-random host selection by anopheline mosquitoes. Parasitol Today 1988, 4:156-162.

20. Saul A: Zooprophylaxis or zoopotentiation: the outcome of introducing animals on vector transmission is highly dependent on the mosquito mortality while searching. Malar $J 2003$, 2:32.

21. Bøgh C, Clarke SE, Pinder M, Sanyang F, Lindsay SW: Effect of passive zooprophylaxis on malaria transmission in The Gambia. J Med Entomol 200I, 38:822-828.

22. Kirby MJ, Green C, Milligan PM, Sismanidis C, Jasseh M, Conway DJ, Lindsay SW: Risk factors for house-entry by malaria vectors in a rural town and satellite villages in The Gambia. Malar J 2008, 7:2.

23. Diatta M, Spiegel A, Lochouarn L, Fontenille D: Similar feeding preferences of Anopheles gambiae and A. arabiensis in Senegal. Trans R Soc Trop Med Hyg 1998, 92:270-272.

24. Fontenille D, Lochouarn L, Diatta M, Sokhna C, Dia I, Diagne N, Lemasson JJ, Ba K, Tall A, Rogier C, Trape JF: Four years' entomological study of the transmission of seasonal malaria in Senegal and the bionomics of Anopheles gambiae and $A$. arabiensis. Trans R Soc Trop Med Hyg 1997, 91 1:647-652.

25. Saul A: Zooprophylaxis or zoopotentiation: the outcome of introducing animals on vector transmission is highly dependent on the mosquito mortality while searching. Malar J 2003, 2:32.

26. Bøgh C, Bøgh C, Clarke SE, Jawara M, Thomas CJ, Lindsay SW: Localized breeding of the Anopheles gambiae complex (Diptera: Culicidae) along the River Gambia, West Africa. Bull Entomol Res 2003, 93:279-287.

Publish with Biomed Central and every scientist can read your work free of charge

"BioMed Central will be the most significant development for disseminating the results of biomedical research in our lifetime. "

Sir Paul Nurse, Cancer Research UK

Your research papers will be:

- available free of charge to the entire biomedical community

- peer reviewed and published immediately upon acceptance

- cited in PubMed and archived on PubMed Central

- yours - you keep the copyright

Submit your manuscript here:

http://www.biomedcentral.com/info/publishing_adv.asp
BiolMedcentral 